\begin{tabular}{ll}
\hline \hline MINING AND METALLURGY INSTITUTE BOR & ISSN: 2334-8836 (Štampano izdanje) \\
UDK: 622 & ISSN: 2406-1395 (Online) \\
\hline \hline
\end{tabular}

Željko Praštalo , Dragan M. Milošević, Jasmina Nešković, Pavle Stjepanović*

\title{
DESIGNING AND PLANNING OF AREAS AFFECTED BY SURFACE DISLOCATIONS AT THE OPEN PITS
}

\begin{abstract}
The designing and spatial planning of areas affected by instability at the open pits represents an analysis of all conditional factors that create a potential representation of a wider area. The specificities that characterize the conditions on the field, created after the instabilities had occurred, require research which along with the calculation results presents a starting point for further design. The terrain leveling, shaping of the slopes and depressions of the open pit, are interpreted based on geological structure, engineering - technical conditions of the work environment, disposition of the existing objects, junctions of the mining area, environmental conditions and factors which add to the stability of the future area. The inclines and slope geometry are defined by the law as well as by the intended purposes of the areas that are to be planned.

The entire area survey for the purpose of its planning should be regarded as a whole which requires the project solutions from multiple technical areas for the purpose of functional area planning. The technological solutions of terrain modeling, taking into consideration the analysis of foundation the acquired results, including the experiences of applied procedures from the subject area, undoubtedly demands synchronization with the technical, technological and capacitive capabilities in a particular case. The definition of technological solutions must be based on the principles of environment preservation.
\end{abstract}

Keywords: ground instability, rehabilitation, design solution

\section{GENERAL OBSERVATION ABOUT THE OPEN PITS OF THE KOSTOLAC COAL BASIN}

Mineral ore exploitation in the Republic of Serbia was conducted in an ambiance of the economic crisis in the past years, which has negatively impacted the mining activities mostly on the economic level. The production processes were reduced to the minimal investments not only in the basic means and maintenance, but in research activities, which along with an inadequate number of workers in production, makes the system barely sustainable. Therefore, because of the insufficient data, which is necessary for the quality technological procedure, and with strict demands for fulfillment the designed coal production, with insufficient investments and bad weather conditions, the production processes are characterized by often work environment instability occurrences.

During previous years, in the area of the Kostolac pits, two cases with the aforementioned hallmarks had appeared.

\footnotetext{
* Mining Institute of Belgrade, Serbia, e-mail: zeljko.prastalo@ ribeograd.ac.rs
} 
First, in the area of the open pit "Ćirikovac" at the end of coal exploitation, a landslide occurred that encompassed a surface of about 30 ha.

Cessation of coal exploitation and repurposing of the area with the designed operation dynamics was made significantly more difficult due to a lack of equipment, work force, changes during activities in the area in question which were conditioned by priority principles. An insufficient number of parameters for reliable planning of the all influential factor for realization the all operations designed for the area of the open pit "Ćirikovac" were made complete by appearance of the aforementioned landslide.

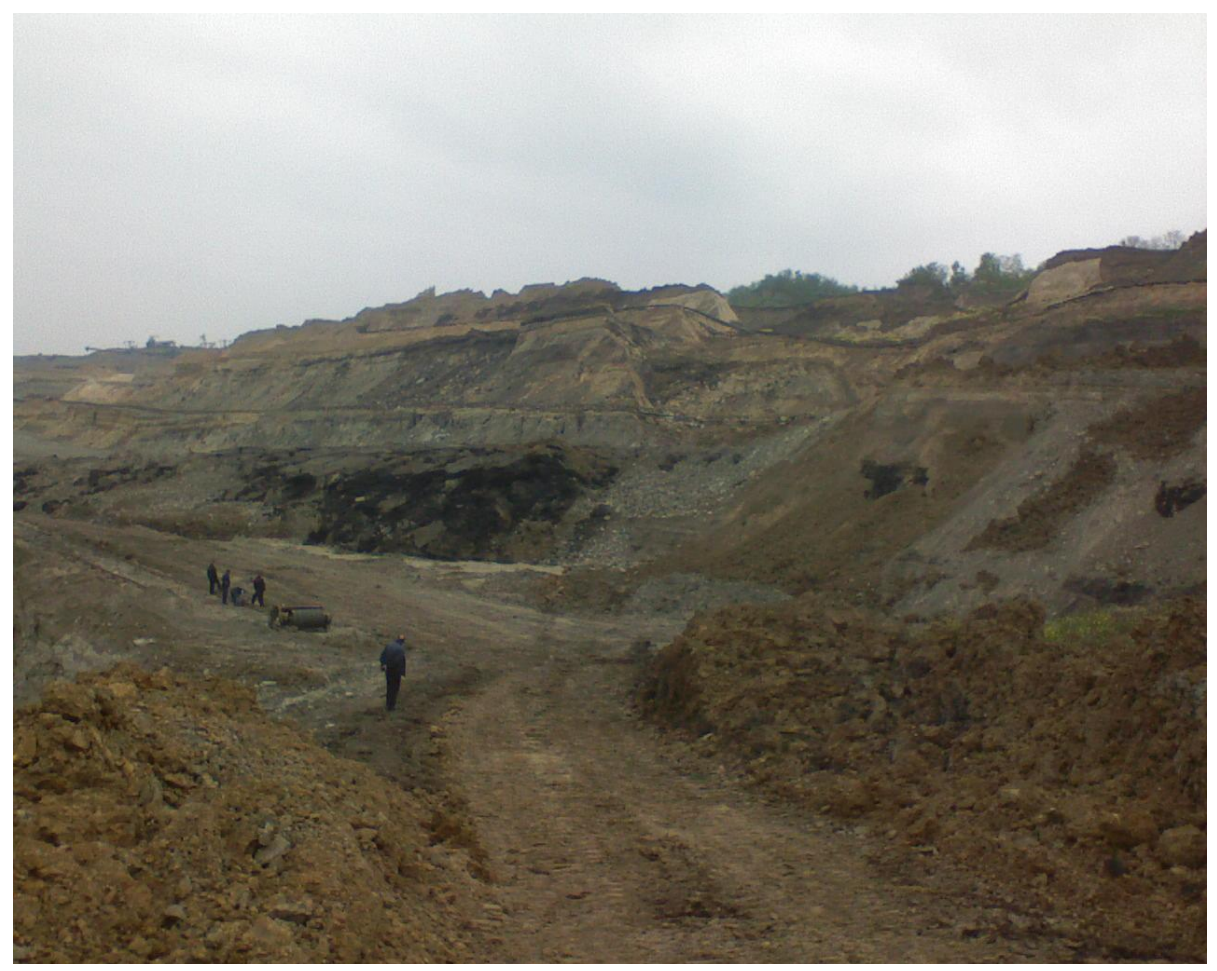

Figure 1 The open pit "Ćirikovac" after surface dislocation

The consequences of bad weather, which have been more frequent in the last couple of years, followed by massive rainfalls in short intervals, during 2014 have conditioned an instability of occurrence on the internal depot of the open pit "Drmno".
Due to this, not only did the short term halts in exploitation occur, but so did the changes that required alterations to the technological procedures and activity dynamics of designed operations. 


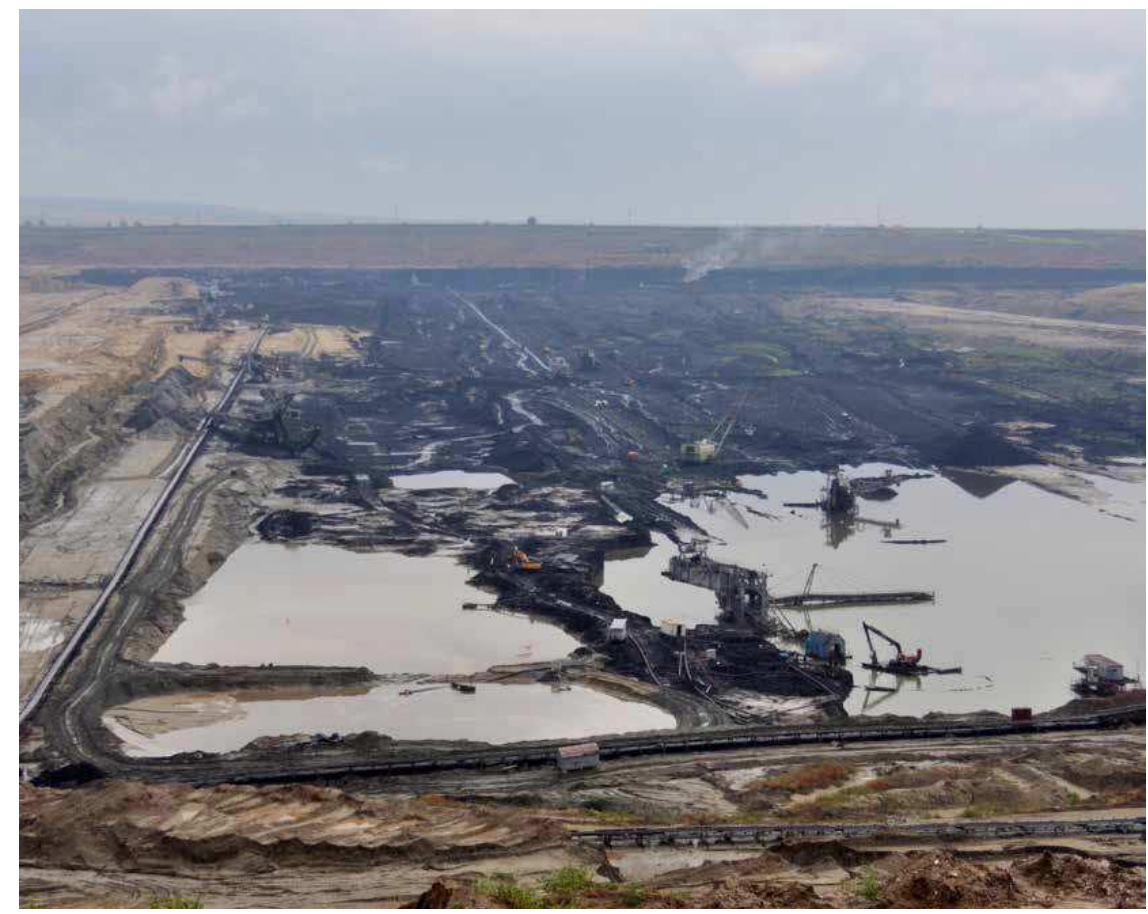

Figure 2 Landscape of the open pit "Drmno" after flooding

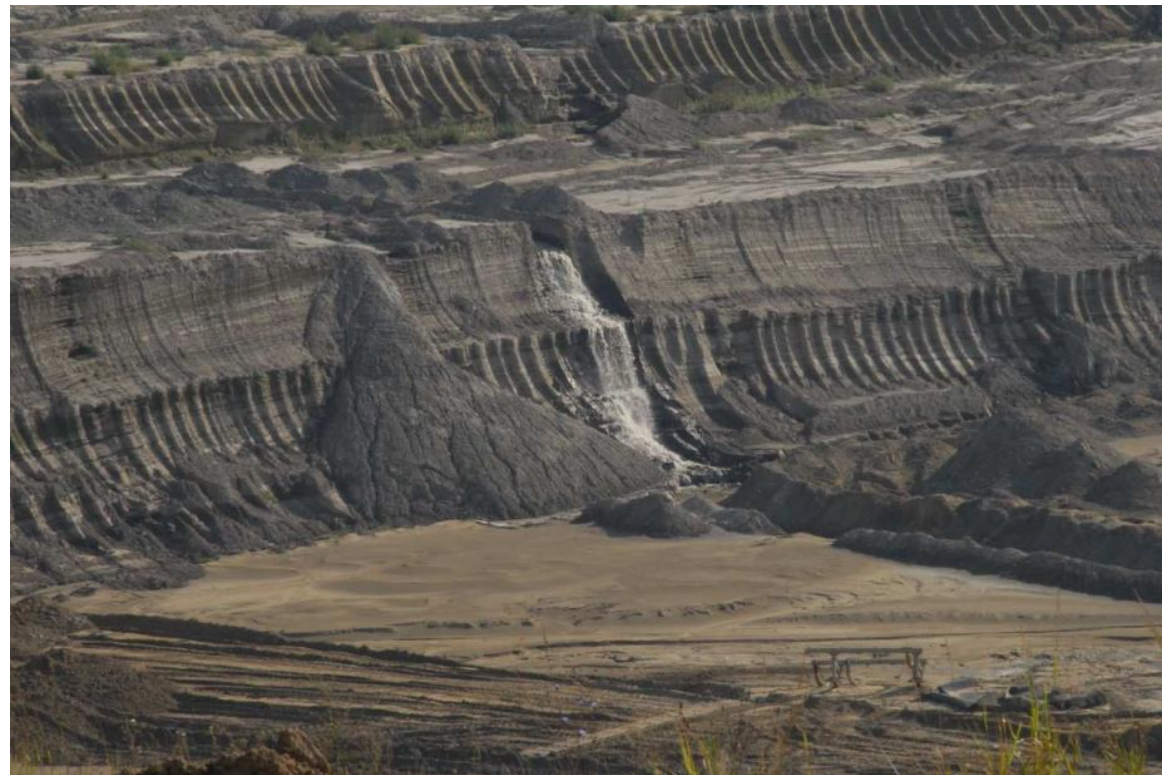

Figure 3 The open pit "Drmno" after the instabilities in the slopes 
The specificity of the information basis, exploitation parameter analysis, as well as the production process itself at the open pits were faintly considered, and the main problems over the past years are as follows:

$\checkmark$ Relatively low exploration degree of certain basins;

$\checkmark$ Lack of complete indicators of work environment;

$\checkmark$ Conditioned production capacities;

$\checkmark$ The necessity for ore homogenization for the purpose of greater quality for the required standards;

$\checkmark$ Inadequate basic equipment maintenance;

$\checkmark$ Insufficient workforce;

$\checkmark$ Dynamic imbalance of the conditions in the field with project solutions;

$\checkmark$ Imbalance in the utilization of the ore base of deposited materials and materials treated as byproducts in our country;

$\checkmark$ Insufficient application of work safety measures;

$\checkmark$ Obsolete legal regulation in the area of mineral ore exploration and in the areas of mining and geology.

\section{INPUT ANALYSIS FOR THE PURPOSE OF QUALITATIVE PLANNING AND DESIGNING SOLUTIONS}

For the purpose of a safer, more efficient, and unimpeded technological exploitation procedure, during the designing of the spatial plans of the area, long-term plans and all other documents, which relate to the landscaping, i.e. the environment in which we live, it is necessary to analyze as large as possible number of elementary and potential factors.

Primarily, it is necessary to harmonize all papers with the project solutions and eventually correct them within the confines of the law. All changes in the technological procedure, activity dynamics, imbalance of conducted and realized technological procedures during exploitation have to be logged, monitored, analyzed and to apply solutions which should provide a safe and continuous operation while taking a great care to protect people and the environment. In this sense, participation and creation the quality applicable solutions with a high degree of responsibility is very important.

Parameter analysis during planning and activity designing at the open pits should encompass several complex areas: geological, hydro-geological, geo-mechanical characteristics of the area, internationally applied experiences from the domain of research and innovative methodologies, the predicted equipment and technological procedure, dynamics and investment-potential specificities as a whole and a basis for the project surface with techno-economic justification. Studying of all these inputs should contribute to the removal of all negative occurrences, which represent potential factors that can contribute to the instability occurrences. Spatial improvement that stopped after the exploitation has stopped should be synchronized with the spatial plan.

Through synthesis of the all elements that characterize the subject area and database creation, variant overview of solutions is enabled and a possibility of choice is created, not applications of conditioned procedures because of circumstances. In this manner, an ambiance of controlled and reliable workforce is created in the confines of legislated safety factors.

Analyzing as great number as possible of functionally connected inputs, knowledge is expanded during activities, with which based on the available resources and with creative design, quality applicable solutions are made.

For quality planning with the purpose of landscaping of the terrain affected by surface dislocation, coordination in synchronization of these fields is necessary during the process of database analysis, during designing. In this sense, it is nece- 
ssary to analyze an area affected by the dislocation during surface exploitation, as well as the surrounding area with all of its elementary specificities - environment characteristics, with obligatory consulting with all laws and codes and regulations on the subject matter.

Technological exploitation procedure should be based on continuous monitoring and analysis of all relevant parameters, in order to prevent an eventual instability occurrence in the work environment. However, in case the aforementioned occurrences do happen, during the designing of dislocated surfaces, it is necessary to analyze the input parameters:

- Description of the area and its surroundings;

- Surfaces with previous exploration results;

- Analysis of designed and achieved activities;

- Geological description;

- Geo-mechanical stability conditions analysis;

- Definition of exploration procedures;

- Data processing;

- Choice of terrain stabilization method;

- Technological activity description;

- Field monitoring methodology after terrain stabilization.

Along with all of this, the obsolete equipment and incapability of application the new technological procedures in function production process efficiency should not be left out.

Because of frequent bad weather conditions, daily hydro-meteorological reports must be kept in everyday information bases of operative units, which beside other basic inputs should represent the basic database to be presented to the top management. In this sense, it is necessary to constantly upgrade the information system with as plentiful data as possible with functional purposes.

\section{CONCLUSION}

Analyzing the instability occurrences at open pit areas, it is primarily necessary to form information systems, which should prevent eventual work space occurrences at the open pit, which are not unavoidable, but always have a reason for occurring.

According to everything described, a continuous exploration and analysis of obtained data, made complete by the weather parameters, should present a foundation of everyday information database of an organizational whole of management the mining complexes.

\section{REFERENCES}

[1] Dražević, D., et al., Supplementary Mining Project of the Pipeline Lane of Dense Hydro-Mixture of Flying and Bottom Ash of the TP "Kostolac B" into the EXCAVATED AREA of the TP "Ćirikovac", Variant South, Mining Institute of Belgrade, 2011 (in Serbian)

[2] Dražević, D., et al., Main Mining Project of Permanent Operations Termination at the Open Pit "Ćirikovac"-Kostolac, Mining Institute of Belgrade, 2012 (in Serbian)

[3] Makar, N., and others, Simplified Mining Landslide Rehabilitation Project at the Excavated Front TP "Ćirikovac", Mining Institute of Belgrade, 2011 (in Serbian)

[4] Makar, N., et al., Technical Mining Project of Combined Operations of the Dragline Dredge and a Bulldozer at the North Slope of theTP "Ćirikovac", Mining Institute of Belgrade, 2015 (in Serbian) 
[5] Pavlović, T., Technical Mining Project if Rehabilitation and Conversion of a Partition Mound Between Cassettes 1 and 2 into a Ridge Mound on the Flying and Bottom Ash Depot "Ćirikovac", Mining Institute of Belgrade, 2014.(in Serbian)

[6] Formánek, Z., et al., Mitigation of Consequences of Disastrous Flooding in the Energy Complex EPS - Serbia, Vodni Zdroje, 2014 (in Serbian)
[7] Milošević. D., et al., Technical Mining Project of Transport and Gypsum Deposition from the Desulphurizing Process of Smoke Gasses of theTP "Kostolac" B1 and B2 into the First Cassette at the Internal Depot of the Open Pit "Drmno", Mining Institute of Belgrade, 2015 (in Serbian)

[8] Makar, N., et al., Study on Stabilization of the Internal Depot Area of the OP "Drmno" for the Purpose of Safe Waste Deposition, Mining Institute of Belgrade, 2015 (in Serbian) 